\title{
'Unexpected infiltration of meninges by generalised diffuse large b-cell lymphoma manifesting as multiple cranial neuropathies in a patient with history of breast carcinoma' - authors' reply
}

\author{
Eva Malá ${ }^{1}$, Kateřina Matějová ${ }^{1}$, Tomáš Olejár ${ }^{2}$, Radoslav Matěj ${ }^{2,3}$, Adam Pavličko $^{4}$, Ondřej Sobek ${ }^{5}$, \\ Robert Rusina ${ }^{1}$ \\ ${ }^{1}$ Department of Neurology, Third Faculty of Medicine, Charles University and Thomayer University Hospital, \\ Prague, Czech Republic \\ ${ }^{2}$ Department of Pathology and Molecular Medicine, Third Faculty of Medicine, Charles University and Thomayer University Hospital, \\ Prague, Czech Republic \\ ${ }^{3}$ Department of Pathology, First Faculty of Medicine, Charles University, and General University Hospital, \\ Prague, Czech Republic \\ ${ }^{4}$ Department of Radiology, Thomayer University Hospital, Prague, Czech Republic \\ ${ }^{5}$ Laboratory for CSF, Neuroimmunology, Pathology and Special Diagnostics, Topelex, Prague, Czech Republic
}

\section{To the Editors}

We recently published in the Polish Journal of Neurology and Neurosurgery a case report entitled 'Unexpected infiltration of meninges by generalised diffuse large B-cell lymphoma manifesting as multiple cranial neuropathies in a patient with a history of breast carcinoma' [1], and a reaction to this paper was submitted [2]. We are very grateful for the interest that our observation has inspired, and we would like to add some comments and details so as to clarify our published text.

We reported leptomeningeal malignant infiltration in a patient with known breast carcinoma initially presenting as a subdural haematoma and multiple cranial nerve neuropathies. The autopsy excluded meningeal carcinomatosis by breast cancer malignant cells, and confirmed generalised B-cell lymphoma with leptomeningeal infiltration.

Our patient had multiple cranial neuropathies attributable to the previously known breast carcinoma, although leptomeningeal infiltration is more frequent in haematological than in solid malignancies [3].

We agree that the MR aspect and its evolution are somewhat troubling. The initial CT scan of the subdural haematoma was performed after the patient had fallen at home, striking her head against a door. At the time, she was taking anticoagulant drugs, so we concluded that the acute subdural haematoma occurred into the area of an older asymptomatic bleeding which had been partially reabsorbed. The MR aspect of haematoma regression with asymmetric meningeal thickening and enhancement can retrospectively be interpreted to mean that the initial traumatic haemorrhage did not occur into a previous asymptomatic subdural haematoma following regression, but rather into the leptomeningeal space infiltrated by tumour cells.

The key cerebrospinal fluid (CSF) examination in CNS tumour involvement is cytology, including immunocytochemical (ICC) identification of tumour cells and flow cytometry (FCM) in haematological malignancies (mainly in lymphomas) [4]. Traditional cytology, ICC, and FCM complement one another. Each method provides a specific piece of information, and so it is convenient to combine them [5].

In our patient, we focused all cytological efforts on the detection and identification of malignant cells. Regarding the expected breast carcinoma infiltration as a possible generalisation of cancer, extensive immunocytochemical testing

Address for correspondence: Robert Rusina, Department of Neurology, Thomayer University Hospital, Vídeňská 800, 140 59 Prague 4, Czech Republic;

e-mail: robert.rusina@lf3.cuni.cz

Received: 23.11.2021 Accepted: 24.11.2021 Early publication date: 4.01.2022

This article is available in open access under Creative Common Attribution-Non-Commercial-No Derivatives 4.0 International (CC BY-NC-ND 4.0) license, allowing to download articles and share them with others as long as they credit the authors and the publisher, but without permission to change them in any way or use them commercially. 
was performed, but FCM was not provided (lymphoma was not suspected at this time). Despite the unexpected detection of cells displaying haematological features in the third lumbar puncture, we could not provide further $\mathrm{CD}$ characterisation, nor quantification of malignant lymphocyte clones by flow cytometry, nor determine the correct diagnosis using only ICC due to the insufficient remaining volume of CSF. The final diagnostic confirmation was made on autopsy, which excluded breast cancer extension and confirmed generalised B-cell lymphoma.

In conclusion, we would like to underline the importance of close interdisciplinary cooperation between clinicians, radiologists, and laboratory specialists, especially in atypical cases. The leading feature in our patient was tumour duplicity, which stressed the importance of aggressively pursuing the possibility of a disorder caused by an entirely new type of tumour. In our patient, this was breast cancer followed by newly developed B-cell lymphoma.

\section{Conflict of interest: None.}

Funding: None.

\section{References:}

1. Malá E, Matějová K, Olejár T, et al. Unexpected infiltration of meninges by generalised diffuse large B-cell lymphoma manifesting as multiple cranial neuropathies in a patient with history of breast carcinoma. Neurol Neurochir Pol. 2021; 55(5): 499-501, doi: 10.5603/PJNNS. a2021.0049, indexed in Pubmed: 34346054.

2. Mrugala MM. Neoplastic meningitis - a puzzling case with important lessons. Neurol Neurochir Pol. 2022; 56(1): 105, doi: 10.5603/ PJNNS.a2022.0001.

3. Hyun JW, Jeong InH, Joung A, et al. Leptomeningeal metastasis: Clinical experience of 519 cases. Eur J Cancer. 2016; 56: 107-114, doi: 10.1016/j.ejca.2015.12.021, indexed in Pubmed: 26841095.

4. Schroers R, Baraniskin A, Heute C, et al. Diagnosis of leptomeningeal disease in diffuse large B-cell lymphomas of the central nervous system by flow cytometry and cytopathology. Eur J Haematol. 2010; 85(6): 520-528, doi: 10.1111/j.1600-0609.2010.01516.x, indexed in Pubmed: 20727005.

5. Dušková J, Sobek O. Assisting the neurologist in diagnosis of CNS malignancies - Current Possibilities and Limits of Cerebrospinal Fluid Cytology and Immunocytochemistry. Brain Behav. 2017; 7(10): e00805, doi: 10.1002/brb3.805, indexed in Pubmed: 29075565. 